\title{
Hepatite lobular dissecante em dois caninos Golden Retriever não relacionados geneticamente
}

\author{
Lobular Dissecting Hepatitis in Two Golden Retriever Dogs Genetically Unrelated \\ Fernando Froner Argenta', Sissy Hobbhahnn', Maria Ines Witz ${ }^{3}$, \\ Luiz Cesar Bello Fallavena ${ }^{2}$ \& Anamaria Telles Esmeraldino ${ }^{2}$
}

\begin{abstract}
Background: Lobular dissecting hepatitis (LDH) is a rare condition of unknown etiology occurring in individuals or in litters of young dogs from some breeds, having poor prognosis and short survival time. Clinically, ascites, weight loss, anorexia, diarrhea and acquired portosystemic shunts are present. Hepatic encephalopathy may also occur. Biochemical blood tests usually show elevated ALT levels. Macroscopically, the liver shows changes in volume, color and regeneration nodules. Histologically, dissection of the parenchyma by connective tissue proliferation leads to disorganization of the liver architecture. The aim of this article is report LDH in two Golden Retriever dogs genetically unrelated.

Cases: Two dogs genetically unrelated and of different owners - Golden Retriever breed - were referred to the Veterinary Medical Teaching Hospital of the Universidade Luterana do Brasil (ULBRA). The first case was a female with 17 months of age and the second, brought to examination one year later, was a male with nine months of age. The clinical signs, in both animals were similar, consisting in intense prostration, inapetence, caquexia and ascites for approximately two weeks. The female dog presented also ataxia, convulsion and diarrhea. Blood examination showed, for both dogs, arregenerative anemia, normal levels of alanine aminotransferase (ALT) and elevated levels of alkaline phosphatase. Total serum protein and albumin were also reduced. Both dogs were euthanized due to their critical condition. The necropsy showed similar lesions in both animals: approximately one liter of a free red colored fluid was observed in the abdominal cavity and hepatic changes consisting in pale green color, smooth surface, firm consistence, yellowish nodules at the surface and tissue proliferation at the margins. There was also congestion of the abdominal visceral veins (portal shunts). Histopathological examination showed, for both dogs, interstitial diffuse fibrosis causing dissection of the parenchyma and isolating hepatocytes in small groups, marked cholestasis and sinusoidal infiltration of inflammatory cells (mainly lymphocytes and plasma cells). Discussion: Lobular dissecting hepatitis is a rare form of hepatic cirrhosis, being unique only to dogs. Some breeds including German Shepherd, Poodle, Rottweiler, Cocker Spaniel and Golden Retriever are considered susceptible to the disease. The clinical signs, age, breed and macroscopic and microscopic lesions presented by the two dogs were consistent with LDH. In this disease, serum biochemistry analyses generally show hypoalbuminemia and increased levels of hepatic enzymes, mainly the ALT. In both animals herein described, albumin levels were decreased, but ALT levels were normal, indicating that a suspicion of this disease should not be discarded in similar cases. ALT levels, as well as of other hepatic enzymes, may not reflect the severity of chronic hepatopathies like LDH, in which the producer cells of this enzyme are being destroyed. These two animals, in spite of pertaining to the same breed, did not presented any genetic relationship, and were owned by different persons. The disease may have a great number of possible etiologies and historical data from the two dogs herein described did not indicated any relevant aspect which could be implicated as a cause of the condition. As affected animals are generally referred to a veterinary consultation in an advanced condition, the cause is difficult to be determined.
\end{abstract}

Keywords: canine, lobular dissecting hepatitis, chronic hepatopathy, unknown etiology.

Descritores: caninos, hepatite lobular dissecante, hepatopatia crônica, etiologia desconhecida. 


\section{INTRODUÇÃO}

A hepatite lobular dissecante (HLD) é uma forma rara de doença hepática crônica de etiologia desconhecida, comumente fatal, que acomete indivíduos ou ninhadas de caninos jovens pertencentes principalmente às raças Golden Retriever, Poodle, Rottweiler, Cocker Spaniel, Pastor Alemão e Mastin Espanhol [2,8,16,18]. A faixa etária varia entre três e 60 meses de idade, e o tempo de sobrevivência é de três a oito semanas [2]. Clinicamente observa-se distensão abdominal por ascite, perda de peso, apatia, diarreia e polidipsia $[1,2,16]$. Sinais de comprometimento nervoso também podem ocorrer, devido à encefalopatia hepática [4,13] . A ocorrência de derivações portossistêmicas múltiplas adquiridas é também comum [8]. Exames bioquímicos geralmente mostram níveis de alanina aminotransferase (ALT) altos e de albumina baixos [2,10].

Macroscopicamente, o fígado pode ter aspecto normal, diminuído de volume ou discretamente tumefeito, pálido, de superfície lisa ou com nódulos de regeneração. Microscopicamente, há dissecação do parênquima hepático por tecido conjuntivo, dividindo e isolando hepatócitos individualmente ou em pequenos grupos, com desorganização da arquitetura normal do órgão [1,2,9]. A inflamação é discreta a moderada, consistindo de infiltração sinusoidal de neutrófilos, linfócitos, plasmócitos e macrófagos [2].

No presente trabalho relatam-se dois casos de hepatite lobular dissecante em caninos da raça Golden Retriever, sem relações de parentesco e pertencentes a diferentes tutores residentes na região metropolitana de Porto Alegre.

\section{CASOS}

Foram atendidos no Hospital Veterinário da Universidade Luterana do Brasil dois caninos da raça Golden Retriever, uma fêmea com um ano e cinco meses de idade (caso 1) e, aproximadamente um ano depois, um macho de nove meses de idade (caso 2), geneticamente não relacionados e de tutores diferentes. Ambos os animais apresentavam histórico clínico de prostração intensa, inapetência, caquexia e aumento de volume abdominal há aproximadamente duas semanas. O caso 1 exibia também ataxia, hiperestesia e aumento de volume dos linfonodos submandibulares e poplíteos, fezes escuras, ataque convulsivo há sete dias e vômito espumoso amarelado. Esse animal também foi descrito como o menor e o mais fraco de uma ninhada de oito filhotes, sendo que os demais se apresentam saudáveis até o momento, com quatro anos de idade.

Ao exame físico, ambos os animais apresentaram intenso desconforto à palpação abdominal, sendo também detectada a presença de líquido livre na cavidade abdominal, caracterizando ascite. O hemograma dos dois animais evidenciou anemia arregenerativa. No caso 1 havia leucocitose (32200/UL) e icterícia moderada. $\mathrm{O}$ exame bioquímico mostrou níveis normais de alanina aminotransferase (ALT) e elevados de fosfatase alcalina (caso $1=218,9 \mathrm{UI} / \mathrm{L}$; caso $2=240,0 \mathrm{UI} / \mathrm{L}$ ). Os níveis de proteína sérica total estavam reduzidos (caso $1=3,9 \mathrm{~g} / \mathrm{dL}$; caso $2=3,8 \mathrm{~g} / \mathrm{dL}$ ) e de albumina (1,2 g/dL para ambos os animais). Em face do estado crítico dos animais e o do acentuado envolvimento hepático recomendou-se a internação para a realização de drenagem abdominal, fluido terapia, analgésicos, antibióticos e suplementação vitamínica. Entretanto, o quadro clínico agravou-se, o caso 1 tendo mais um episódio convulsivo, vômito e diarreia escuros e, ao terceiro dia, edema facial. Por causa do prognóstico desfavorável e da situação crítica apresentada, ambos os animais foram eutanasiados e encaminhados ao Setor de Patologia Veterinária, onde foram necropsiados.

À necropsia, os achados macroscópicos em ambos os animais incluíram mucosas hipocoradas a discretamente ictéricas, anasarca e presença de aproximadamente dois litros de líquido translúcido a discretamente rosado na cavidade abdominal. $\mathrm{O}$ fígado apresentava-se pálido a esverdeado, diminuído de volume e de consistência firme, com evidenciação do padrão lobular e superfície contendo nódulos de diâmetro variável e coloração pardacenta, além de margens com proliferação tecidual (Figura 1). Múltiplas derivações portossistêmicas adquiridas, tortuosas e de aspecto varicoso, comunicando principalmente as tributárias intestinais e esplênicas da veia porta, foram também observadas em ambos os cães. Os pulmões apresentavam-se edemaciados, com a superfície pleural brilhante e de coloração avermelhada, sendo que ao corte fluía líquido serossanguinolento. Amostras foram coletadas, fixadas em formalina $10 \%$ e processadas pela técnica rotineira de inclusão em parafina. Secções de quatro micrometros de espessura foram coradas pelas técnicas da hematoxilina e eosina, tricrômico de Masson para evidenciação de tecido conjuntivo e ácido rubeânico para visualização de grânulos de cobre [7]. 
O exame microscópico do fígado, no caso 1 , mostrou fibrose intersticial difusa que isolava os hepatócitos, colestase acentuada e inflamação sinusoidal; havia dissecação do parênquima por finas fibras colágenas separando os hepatócitos em pequenos grupos, com infiltração de células inflamatórias (principalmente linfócitos e plasmócitos). No caso 2, o fígado também apresentou desorganização da arquitetura normal, com áreas de regeneração e degeneração gordurosa acentuada, fibrose e infiltração de células inflamatórias (Figura 2). Nesse último animal havia também pneumonia intersticial. A coloração pelo método tricrômico evidenciou a proliferação de tecido conjuntivo fibroso no parênquima hepático. A coloração pelo ácido rubeânico não evidenciou grânulos de cobre. Os pulmões evidenciaram congestão e edema acentuados.

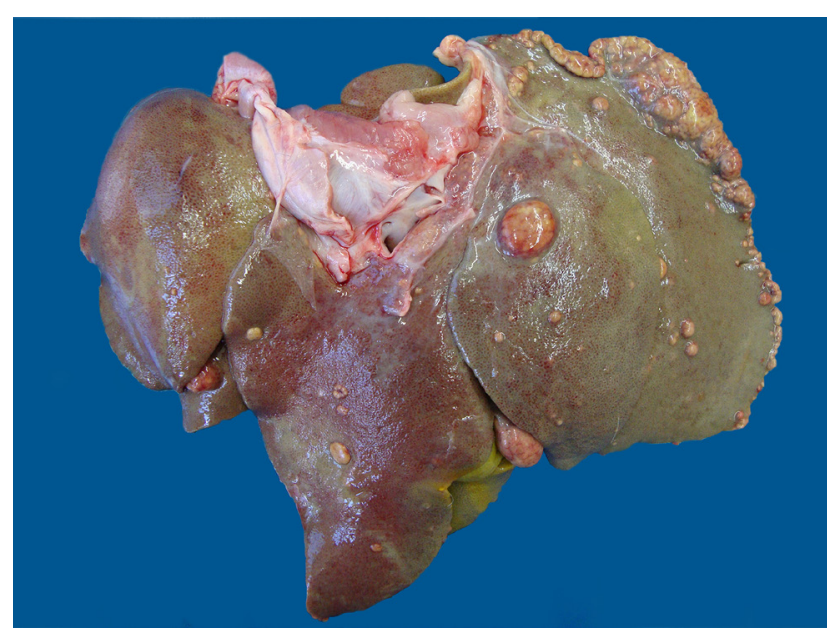

Figura 1. Aspecto macroscópico do fígado de um canino com hepatite lobular dissecante, mostrando superfície capsular com múltiplos nódulos de diâmetro variável. Proliferação tecidual marginal.

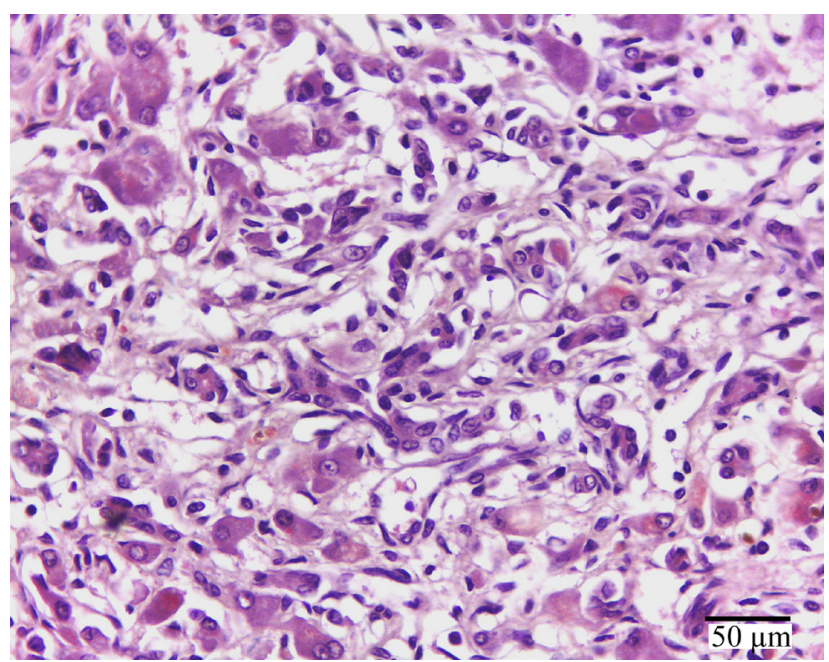

Figura 2. Intensa fibrose separando hepatócitos individualmente ou em pequenos grupos $(\mathrm{HE})$. [Barra $50 \mu \mathrm{m}$ ].

\section{DISCUSSÃO}

No presente relato, a sintomatologia clínica e os achados macroscópicos e microscópicos em ambos os animais foram semelhantes aos descritos para a hepatite lobular dissecante, assim como a faixa etária [2,18]. A HLD é considerada uma hepatite idiopática que ocorre somente em caninos, evidenciando comportamento clínico e histológico peculiar, tendo progressão aguda e sendo caracterizada histologicamente como hepatite crônica, devido à extensa fibrose [6].

Uma predisposição racial tem sido relatada, incluindo-se a raça Golden Retriever, dentre outras [2]. Nos dois casos ora relatados, os animais não possuíam relação familiar e pertenciam a tutores diferentes, também não havendo histórico de envolvimento de outros possíveis fatores como doença infecciosa, toxinas ou utilização de medicamentos [20]. Os sinais clínicos apresentados por ambos os animais, tais como distensão abdominal por ascite, perda de peso, apatia e diarreia são comuns nos casos de HLD [2,19]. Os sinais neurológicos observados no caso 1 estão relacionados com encefalopatia hepática, ocorrência frequente em pacientes com hepatopatia grave, em que a concentração de amônia circulante aumenta $[3,4,16]$.

Com relação aos exames bioquímicos, uma elevação marcante nos níveis das enzimas hepáticas, especialmente a ALT ocorre nos casos de lesão hepática $[1,17]$. No presente trabalho, os níveis de ALT estavam dentro dos parâmetros normais, indicando que uma suspeita de HLD não deve ser descartada quando os níveis dessa enzima não estão elevados. Os valores de ALT nem sempre refletem a gravidade da lesão hepática, especialmente quando se considera que a HLD é uma doença crônica, em que as células produtoras dessa enzima (os hepatócitos) foram em grande parte substituídas por tecido conjuntivo [14]. A fosfatase alcalina aumentada indica doença hepática obstrutiva, em que há diminuição na excreção biliar desta enzima $[11,17]$. Também a hipoalbuminemia observada nos casos ora descritos é causada por deficiência na síntese dessa proteína pelo fígado lesado, sendo esse achado considerado um indicador mais confiável nos casos de doença crônica hepática $[11,14]$.

Os achados macroscópicos evidenciam insuficiência hepática crônica, com as derivações portossistêmicas decorrendo do aumento na resistência intra-hepática causada pela fibrose. Tais derivações são comuns em quadros de cirrose, assim como tam- 
bém é frequente o aparecimento de ascite e edema subcutâneo $[2,4,10,12]$.

Nos casos ora descritos, não se detectou a presença de cobre no fígado. As lesões microscópicas em ambos os animais diferem daquelas encontradas em casos de acúmulo de cobre, pois nestes últimos, a fibrose é periacinar [12], enquanto que na HLD a proliferação de tecido conjuntivo disseca o parênquima hepático, dividindo e isolando os hepatócitos individualmente ou em pequenos grupos. Além disso, o acúmulo de cobre não é um fenômeno consistente na hepatite lobular dissecante pois, quando ocorre, é provavelmente secundário à colestase [19].

No que diz respeito à HLD, sugere-se que a expressão, entre os hepatócitos, de uma matriz extracelular contendo principalmente fibronectina e laminina, em associação com a proliferação de fibras colágenas e reticulares desempenha papel preponderante na ruptura dos cordões de hepatócitos e no desaparecimento destes [8]. A intensa fibrose parece interferir de alguma maneira com a diferenciação/maturação das células hepáticas progenitoras que, na HLD, proliferam intensamente no parênquima hepático [6]. Estudos sobre a etiopatogenia dessa doença são necessários para a tomada de medidas de prevenção e tratamento [5], assim como poderiam auxiliar a esclarecer a forma pela qual as células progenitoras hepáticas contribuem para a progressão da fibrose e a sua potencial contribuição negativa para a regeneração hepática nos casos de hepatopatias crônicas.

Os casos de HLD descritos no presente relato servem de alerta para que esta doença seja considerada como hipótese diagnóstica em caninos jovens com sinais de comprometimento hepático, mesmo quando os níveis de ALT estejam dentro dos parâmetros normais.

Declaration of interest. The authors report no conflicts of interest. The authors alone are responsible for the content and writing of the paper.

\section{REFERENCES}

1 Barros C.S.L. 2016. Fígado, Vias Biliares e Pâncreas Exócrino. In: Santos R.L. \& Alessi A.C. (Eds). Patologia Veterinária. 2.ed. Rio de Janeiro: Roca, pp.181-265.

2 Bennett A.M., Davies J.D., Gaskell C.J. \& Lucke V.M. 1983. Lobular dissecting hepatitis in the dog. Veterinary Pathology. 20(2): 179-188.

3 Bunch S.E. 1991. Hepatic encephalopathy. Progress in Veterinary Neurology. 2(4): 287-296.

4 Cullen J.M. \& Brown D.L. 2012. Hepatobiliary System and Exocrine Pancreas. In: McGavin M.D. \& Zachary J.F. (Eds). Pathologic Basis of Veterinary Disease. 5th edn. St. Louis: Elsevier Mosby, pp.405-453.

5 Favier R.P. 2009. Idiopathic hepatitis and cirrhosis in dogs. Veterinary Clinics of North America: Small Animal Practice. 39(3): 481-488.

6 Kruitwagen H.S., Spee B. \& Schotanus B.A. 2014. Hepatic progenitor cells in canine and feline medicine: potential for regenerative strategies. BMC Veterinary Research. 10: 137.

7 Luna L.G. 1968. Manual of histologic staining methods of the Armed Forces Institute of Pathology. 13th edn. New York: McGraw-Hill, 258 p.

8 Mizooku H., Kagawa Y., Matsuda K., Okamoto M. \& Taniyama H. 2013. Histological and Immunohistochemical Evaluations of Lobular Dissecting Hepatitis in American Cocker Spaniel Dogs. Journal of Veterinary Medical Association. 75(5): 597-603.

9 Poldervaart J.H., Favier R.P., Penning L.C., Van Den Ingh T.S.G.A.M. \& Rothuizen J. 2008. Primary Hepatitis in Dogs: a retrospective review (2002-2006). Journal of Veterinary Internal Medicine. 23(1): 72-80.

10 Rothuizen J. 2009. Important clinical syndromes associated with liver disease. Veterinary Clinics of North America: Small Animal Practice. 39(3): 419-437.

11 Sevelius E. 1995. Diagnosis and prognosis of chronic hepatitis and cirrhosis in dogs. Journal of Small Animal Practice. 36(12): 521-528.

12 Stalker M.J. \& Hayes M.A. 2007. Liver and Biliary System. In: Maxie M.G. (Ed). Jubb, Kennedy, and Palmer's Pathology of Domestic Animals. v.2. 5th edn. Philadelphia: Elsevier Saunders, pp.297-388.

13 Sterczer A., Gaa E., Perge E. \& Rothuizen J. 2011. Chronic hepatitis in the dog: a review. Veterinary Quarterly. 23: 148-152.

14 Sutherland R.J. 1989. Biochemical evaluation of the hepatobiliary system in dogs and cats. Veterinary Clinics of North America: Small Animal Practice. 19(5): 899-927. 
F.F. Argenta, S. Hobbhahn, M.I. Witz, L.C.B. Fallavena \& A.T. Esmeraldino. 2017. Hepatite lobular dissecante em dois caninos Golden Retriever não relacionados geneticamente. Acta Scientiae Veterinariae. 45(Suppl 1): 216.

15 Tams T.R. 1985. Hepatic encephalopathy. Veterinary Clinics of North America: Small Animal Practice. 15(1): 177-195. 16 Tennant B.C. \& Center S.A. 1997. Hepatic Function. In: Kaneko J.J., Harvey J.W. \& Bruss M.C. (Eds). Clinical Biochemistry of Domestic Animals. 6th edn. San Diego: Academic Press, pp.351-379.

17 Thrall M.A., Baker D.C., Campbell T.W., De Nicola D., Fettman M.J., Lassen E.D., Rebar A. \& Weiser G. 2007. Hematologia e Bioquímica Clínica Veterinária. Rio de Janeiro: Roca, 582p.

18 Twedt D.C. 1985. Cirrhosis: a consequence of chronic liver disease. Veterinary Clinics of North America: Small Animal Practice. 15(1): 151-176.

19 Van den Ingh T. \& Rothuizen J. 1994. Lobular dissecting hepatitis in juvenile and young adult dogs. Journal of Veterinary Internal Medicine. 8(3): 217-220.

20 Watson P.J. 2004. Chronic hepatitis in dogs: a review of current understanting of the aetiology, progression and treatment. The Veterinary Journal. 167(3): 228-241. 